\title{
Biochemical markers of bone metabolism in children with cow's milk allergy
}

\author{
Jadwiga Ambroszkiewicz' Grażyna Rowicka², Magdalena Chelchowska ${ }^{1}$, Joanna Gajewska ${ }^{1}$, \\ Małgorzata Strucińska², Teresa Laskowska-Klita²
}

1Screening Department, Institute of Mother and Child, Warsaw, Poland

2Department of Nutrition, Institute of Mother and Child, Warsaw, Poland

\begin{abstract}
Submitted: 18 September 2012
Accepted: 30 October 2012
\end{abstract}

Arch Med Sci 2014; 10, 6: 1135-1141

DOI: 10.5114/aoms.2013.36906

Copyright @ 2014 Termedia \& Banach

\section{Abstract}

Introduction: Patients with cow's milk allergy (CMA) and following a cow milk protein-free diet for a long time are potentially at risk of developing bone abnormalities. To assess the balance between bone formation and resorption processes, we determined serum concentrations of osteocalcin (OC), bone alkaline phosphatase (BALP), C-terminal telopeptide of type I collagen (CTX), fetuin-A, osteoprotegerin (OPG) and receptor activator of nuclear factor $\kappa B$ ligand (RANKL) in children with CMA.

Material and methods: The study included 50 prepubertal children with diagnosed cow's milk allergy, who were under systematic medical and nutritional care at the Institute of Mother and Child and 40 healthy counterparts as a control group. The concentrations of bone metabolism markers were determined by immunoenzymatic assays.

Results: The diets of all investigated children were correct in terms of phosphorus and magnesium contents but deficient in terms of calcium and vitamin D. Serum OC and CTX as well as fetuin-A concentrations were similar in both studied groups. The BALP activity was significantly $(p<0.05)$ higher in children with cow's milk allergy than in the controls. Serum OPG concentration was comparable in both groups, but the RANKL level was higher $(p<0.05)$ in CMA children than in healthy ones. Hence, the ratio of OPG/RANKL was lower in children with CMA. Conclusions: Our study demonstrates slight disturbances in the profile of bone metabolism markers in growing children with CMA. The increase in RANKL level and decrease in OPG/RANKL ratio may contribute to intensification of bone resorption in these patients.

Key words: bone turnover markers, OPG/RANK/RANKL system, fetuin-A, cow's milk allergy.

\section{Introduction}

The most common food allergens responsible for allergic diseases among infants and young children are cow's milk proteins. The cumulative incidence of diagnosed cow's milk allergy ranges between $2 \%$ and $7 \%$ in western societies [1, 2]. The only proven treatment consists of elimination of cow milk protein from the child's diet and introduction of formulas based on extensively hydrolyzed proteins and soy products [3, 4]. These formulas may be tolerated differently by children, whose diets are therefore sometimes deficient in necessary nutrients. What is more, it may

\author{
Corresponding author: \\ Jadwiga Ambroszkiewicz PhD \\ Screening Department \\ Institute of Mother and Child \\ 17 A Kasprzaka St \\ 01-211 Warsaw, Poland \\ Phone: +48 505029758 \\ +4822327 2260 \\ Fax: +48 223277260 \\ E-mail: \\ bioklin.imid@imid.med.pl
}


adversely affect bone metabolism, especially in the period when growth and development occur intensively.

Traditionally, the assessment of bone status is done using densitometry techniques, recognized as a gold standard. However, these measures do not reflect the dynamics of bone tissue [5]. Biochemical bone turnover markers showing global skeletal activity are useful in the assessment of the dynamics of bone formation and resorption processes. Among bone markers, special attention should be paid to osteocalcin (OC) and bone alkaline phosphatase (BALP) as indicators of bone formation, and C-terminal telopeptide of type I collagen (CTX) as one of the markers of bone resorption. Many factors influence the bone marker levels, such as age, gender, pubertal stage and nutritional status. The widespread applicability of bone metabolism markers is limited by the availability of normative data. In contrast to adults, children have increased bone marker concentrations due to their skeletal growth velocity and high rate of bone turnover [6-9].

The overall rate of bone remodeling depends on the RANK/OPG/RANKL cytokine system. Osteoprotegerin (OPG), receptor activator of nuclear factor $\kappa B(R A N K)$ and its ligand (RANKL) are indicators of regulation of osteoblast and osteoclast activity. When the balance between OPG and RANKL expression favors OPG, bone resorption is inhibited and bone formation dominates, but when it favors RANKL, bone resorption predominates and leads to bone loss [10-12]. According to recent reports, fetuin-A also plays a role in the regulation of calcium-phosphate balance. This protein, of hepatic origin, circulates in large amounts in serum, but is also expressed in bone. Accumulation of fetuin-A in bone is high due to strong affinity with hydroxyapatite, but its effect on bone formation and mineralization processes is not fully understood. It may act as an inhibitor of the transforming growth factor $\beta$ (TGF- $\beta$ ) and bone morphogenetic protein complex. Based on the studies conducted on adults, it was found that there is a correlation between serum fetuin- $A$ and bone mineral density (BMD) $[13,14]$.

To our knowledge, minimal data exist concerning concentrations of biochemical bone metabolism markers in children with cow's milk allergy (CMA) $[15,16]$. No research has been done regarding the levels of cytokines OPG and RANKL as well as levels of fetuin-A on this group of children. The aim of this study was to assess the balance between bone formation and bone resorption processes using biochemical bone turnover markers, and to determine the relation between OPG and RANKL in the regulation of bone metabolism in children with cow's milk allergy.

\section{Material and methods}

This study involved children in the prepubertal period of life. The study group consisted of children with confirmed cow's milk allergy who visited the Gastroenterology Clinic at the Institute of Mother and Child in Warsaw between July 2010 and June 2012. Cow's milk allergy was identified based on generally accepted standards: the presence of clinical symptoms of an allergy, elevated serum-specific immunoglobulin E, positive results of skin-prick test, and positive results of open oral milk challenge test. The children had been on a dairy-free diet for at least a year and remained under medical and nutritional care.

The control group matched for age and gender was recruited from children who had no symptoms of CMA, or any diseases that might affect bone metabolism. All the studied children were followed up as outpatients. They were not taking any bone sparing drugs and did not have bone fractures. To exclude the effects of puberty on bone metabolism markers, only prepubertal subjects were included in the study.

Anthropometric parameter measurements (weight, height) were performed for all children and body mass index (BMI) was calculated using the formula weight $(\mathrm{kg}) / \mathrm{height}\left(\mathrm{m}^{2}\right)$. The obtained $\mathrm{BMI}$ value was related to the Polish age-and-gender specific BMI centile charts and BMI z-scores were calculated [17]. Dietary intake of macro- and micronutrients was assessed based on 3-day records including 1 weekend day using the Dietetyk $2^{\circledR}$ computer software. The obtained results were compared to the current recommendations for the supply of essential nutrients for the Polish population [18].

For biochemical assay peripheral blood was taken in the morning hours. In the serum samples concentrations of protein, calcium, phosphate, magnesium and total alkaline phosphatase (ALP) were measured by standard enzymatic methods using a biochemical automated analyzer. The level of vitamin D (as 25-hydroxyvitamin D) was determined by chemiluminescence immunoassay using kits from DiaSorin (USA). Intra-and inter-assay precisions of this method were $9.4 \%$ and $10.8 \%$, respectively. Remaining serum samples were preserved at $-20^{\circ} \mathrm{C}$ for later examination. Serum concentrations of bone metabolism markers were determined (essentially as described by the manufacturer) by immunoenzymatic ELISA assay. Levels of BALP and OPG were measured using available kits from Quidel (USA), of fetuin-A using kits from Epitope Diagnostics (USA), and of RANKL (total sRANKL) using kits from ImmunoDiagnostics (Germany). Intra- and inter-assay coefficients of variation of these methods were lower than $10 \%$. Serum OC concentration was measured by N-Mid Osteocalcin ELISA assay (IDS, UK), which detects both the 
$\mathrm{N}$-mid fragment as well as the N-terminal fragment of osteocalcin in serum. The intra-and inter-assay coefficients for variation in this method were $4 \%$ and $6.5 \%$, respectively. Serum concentration of CTX was determined by Serum CrossLaps ELISA assay (IDS, UK), in which antibodies recognize linear $\beta$-octapeptides of type I collagen (the intra- as well as inter-assay coefficient of variation was $4.6 \%$ ).

\section{Statistical analysis}

Statistical analyses were performed using the Statistica software program, version 10.0 PL. Distributions were assessed for normality using the Shapiro-Wilk test. The symmetrically distributed data are expressed as mean \pm standard deviation (SD) and the asymmetrically distributed data as median with $25^{\text {th }}$ and $75^{\text {th }}$ centiles. Student's $t$ test was used to calculate the differences between means and the Mann-Whitney $U$ test was used to compare asymmetric variables. Pearson's or Spearman's rank correlation tests were used to evaluate the possible relationships between various parameters. The statistical significance was set at $p<0.05$.

The study protocol was approved by the Ethics Committee of the Institute of Mother and Child. Written informed consent was obtained from parents of all examined children.

\section{Results}

In total, 90 children aged 3-6 years were recruited to this study. Among them, the study group consisted of 50 children (17 girls and 33 boys, mean age
$4.7 \pm 1.3$ years, range $3-6$ years) with diagnosed cow's milk allergy. The patients had different initial symptoms: $50 \%$ of them had atopic dermatitis, $50 \%$ showed gastrointestinal symptoms, and $50 \%$ had recurrent respiratory tract infections. Some patients $(46 \%)$ had only one symptom, while in the others (54\%) different organ systems were affected. The median age at which cow's milk allergy was diagnosed was 7.5 (3-18) months. They had been treated with an elimination diet, providing a milk substitute: extensively hydrolyzed formulas in 27 patients (54\%) and soy-based formulas in 23 patients (46\%). The control group consisted of 40 healthy children matched for age and gender (17 girls, 23 boys, mean age $4.7 \pm 1.6$ years, range $3-6$ years) whose diets included milk and dairy products.

The anthropometric characteristics and nutrient intakes of studied children are summarized in Table I. Generally, the growth of all children was correct and there were no significant differences in body weight, height, BMI index and BMI z-score between children with cow's milk allergy and the controls. Total energy and percentage of energy from macronutrients in diets of all children were within the recommended daily intake. The patients with CMA had a significantly $(p<0.05)$ lower intake of fat and higher $(p<0.05)$ intake of carbohydrate compared to the controls. The diets of all the investigated children were correct in terms of fiber, phosphorus, and magnesium contents but deficient in terms of calcium and vitamin D. About $50 \%$ of patients with allergy had dietary calcium intake lower than $400 \mathrm{mg} /$ day and vitamin D intake below

Table I. Anthropometric characteristic and dietary intake of children with CMA and control children

\begin{tabular}{|c|c|c|c|}
\hline Parameter & Children with CMA & Control children & Value of $p$ \\
\hline$n$ & 50 & 40 & \\
\hline Age [years] $^{*}$ & $4.7 \pm 1.3$ & $4.7 \pm 1.6$ & 0.9165 \\
\hline Body mass $[\mathrm{kg}]^{*}$ & $17.4 \pm 3.6$ & $17.5 \pm 4.3$ & 0.8568 \\
\hline Body height $[\mathrm{cm}]^{*}$ & $108.2 \pm 10.3$ & $108.6 \pm 12.2$ & 0.8479 \\
\hline BMI $\left[\mathrm{kg} / \mathrm{m}^{2}\right]^{*}$ & $14.6 \pm 1.5$ & $14.7 \pm 1.3$ & 0.7644 \\
\hline BMI z-score ${ }^{\star}$ & $-0.74 \pm 0.89$ & $-0.72 \pm 0.93$ & 0.8646 \\
\hline \multicolumn{4}{|l|}{ Dietary intake: } \\
\hline Total energy $[\mathrm{kcal} / \mathrm{day}]^{\star *}$ & $1374(1121-1497)$ & $1404(1145-1585)$ & 0.4819 \\
\hline Protein [\%] ${ }^{*}$ & $13.4 \pm 2.7$ & $14.5 \pm 2.8$ & 0.0811 \\
\hline Fat [\%] & $30.4 \pm 6.8$ & $33.6 \pm 5.3$ & 0.0191 \\
\hline Carbohydrate $[\%]^{*}$ & $56.5 \pm 8.0$ & $51.9 \pm 5.9$ & 0.0411 \\
\hline Calcium [mg/day] $]^{\star *}$ & $400(301-589)$ & $461(291-621)$ & 0.2849 \\
\hline Phosphorus [mg/day] $]^{\star *}$ & $707(524-872)$ & $702(603-895)$ & 0.2817 \\
\hline Magnesium [mg/day ${ }^{*}$ & $181.6 \pm 54.6$ & $169.5 \pm 45.7$ & 0.5881 \\
\hline Vitamin $D[\mu g / d a y]^{* *}$ & $5.2(2.6-6.6)$ & $2.1(1.3-2.9)$ & 0.0007 \\
\hline Fiber $[\mathrm{g} / \text { day }]^{\star *}$ & $14.7(11.1-16.8)$ & $10.9(9.3-13.5)$ & 0.1379 \\
\hline
\end{tabular}

${ }^{*}$ Data are presented as mean values $\pm S D,{ }^{* *}$ data are presented as median values and ranges (25-75\%). 
Table II. Serum concentrations of biochemical bone metabolism parameters in children with CMA and in controls

\begin{tabular}{|lccc|}
\hline Parameter & Children with CMA & Control children & Value of $p$ \\
\hline Calcium $[\mathrm{mmol} /]^{*}$ & $2.44 \pm 0.11$ & $2.46 \pm 0.09$ & 0.5900 \\
\hline Phosphate $[\mathrm{mmol} /]^{*}$ & $1.55 \pm 0.14$ & $1.58 \pm 0.016$ & 0.4215 \\
\hline Magnesium $[\mathrm{mmol} /]^{*}$ & $0.85 \pm 0.06$ & $0.85 \pm 0.05$ & 0.8762 \\
\hline 25-hydroxyvitamin D $[\mathrm{ng} / \mathrm{ml}]^{*}$ & $26.7 \pm 8.9$ & $27.7 \pm 9.7$ & 0.6296 \\
\hline ALP $[\mathrm{U} / \mathrm{l}]^{*}$ & $228.5 \pm 51.3$ & $224.3 \pm 41.9$ & 0.6683 \\
\hline BALP $[\mathrm{U} / \mathrm{l}]^{*}$ & $140.8 \pm 30.3$ & $123.7 \pm 21.5$ & 0.0023 \\
\hline OC $[\mathrm{ng} / \mathrm{ml}]^{\star *}$ & $61.8(50.6-76.2)$ & $58.3(46.4-69.3)$ & 0.0922 \\
\hline CTX $[\mathrm{ng} / \mathrm{ml}]^{\star *}$ & $1.32(1.12-1.70)$ & $1.26(1.09-1.66)$ & 0.8352 \\
\hline Fetuin-A $[\mathrm{g} /]^{*}$ & $0.41 \pm 0.09$ & $0.43 \pm 0.11$ & 0.3176 \\
\hline OPG $[\mathrm{pmol} / \mathrm{l}]^{*}$ & $4.27 \pm 1.05$ & $4.45 \pm 1.04$ & 0.4478 \\
\hline RANKL $[\mathrm{pmol} /]^{* *}$ & $1547(929-2844)$ & $1262(996-2782)$ & 0.0485 \\
\hline Ratio of OPG/RANKL* & $0.29 \pm 0.12$ & $0.42 \pm 0.23$ & 0.0414 \\
\hline
\end{tabular}

Data shown as mean $\pm S D ;{ }^{*}$ For normal or median and range (25-75\%), ${ }^{* *}$ for non-normal variables; ALP - alkaline phosphatase, BALP - bone alkaline phosphatase, OC - osteocalcin, CTX - C-terminal telopeptide of type I collagen, OPG - osteoprotegerin, RANKL - receptor activator of nuclear factor $\kappa B$ ligand.

$5 \mu \mathrm{g} /$ day. None of the control children were supplemented with vitamin D and only 6 patients with CMA were supplemented (vitamin D: 200-400 IU).

Serum concentrations of biochemical bone metabolism parameters in children with cow's milk allergy and in their healthy counterparts are presented in Table II. There was no significant difference in serum calcium, phosphate and magnesium concentrations between both studied groups of children. Overall vitamin D status was within reference values in the majority of the studied children. There was no significant difference in the activity of total ALP between patients and controls but activity of BALP was significantly higher in CMA children $(p<0.01)$. Serum concentrations of OC and CTX were comparable in both groups of children. The levels of OPG were similar in both groups of children, whereas RANKL was significantly higher in cow milk-sensitive children $(p<0.05)$. Hence, the ratio of OPG/RANKL was about $20 \%$ lower in children with allergy compared to their healthy counterparts. Serum fetuin-A concentrations did not differ in the two studied groups.

We found positive correlations between dietary vitamin D intake and serum 25 -hydroxyvitamin D concentrations in children with cow's milk allergy $(r=0.4005, p<0.01)$ and in the controls $(r=0.4301$, $p<0.01)$. Additionally, dietary vitamin $\mathrm{D}$ intake correlates $(p<0.01)$ with serum concentration of OPG in both groups of children ( $r=0.3911$ in CMA and $r=0.4402, p<0.05$ in control group). In children with cow's milk allergy, we observed a relationship between serum calcium concentration and ALP $(r=0.4746, p<0.001)$ as well as BALP $(r=0.4128$, $p<0.01)$. Moreover, we found positive correlations between ALP and BALP $(r=0.6250, p<0.0001$ in
CMA children and $r=0.4181, p<0.01$ in controls) and between OC and CTX $(r=0.5034, p<0.001$ in CMA children and $r=0.4221, p<0.01$ in controls). Other parameters did not correlate with each other.

\section{Discussion}

Bones are constantly undergoing a remodeling process that involves hormones, proteins, calcium, phosphate, vitamin D, and other vitamins and minerals. Proper nutrition is important for the acquisition of peak bone mass, especially in childhood and adolescence, when growth and development are intensive. Adequate calcium and vitamin D intake is important for children, especially those who might have deficiencies attributable to milk allergy [19-21]. Despite the active research, evidence on the association between allergic diseases and bone status is not consistent. Studies concerning bone mineralization showed normal or decreased bone mineral content (BMC) and BMD in patients with food allergy [22-26]. In a Spanish study, 50\% of children on a low-milk diet had osteopenia or osteoporosis [24]. In the study of Hidvegi et al. [15] about $30 \%$ of children with CMA had decreased bone mineral density.

Generally, the proportions of energy supplied as protein, fat and carbohydrate in our studied children were in accordance with the recommendations. However, the patients with CMA had lower intake of fat and higher intake of carbohydrate compared to the controls. Our group of children with CMA was followed carefully by a pediatrician and nutritionist. In spite of this, signs of inadequate nutrition were seen. In all the studied children we observed low intake of calcium and very low intake 
of vitamin D as compared to the recommended values. About $50 \%$ of patients with allergy had dietary calcium intake lower than $400 \mathrm{mg} /$ day and only $6 \%$ had intake above $800 \mathrm{mg} /$ day. Among the controls, $30 \%$ of children had dietary calcium intake lower than $400 \mathrm{mg} /$ day and $18 \%$ of children had intake above $800 \mathrm{mg} /$ day. It was found that calcium intake was positively correlated with bone mineral density. Henderson et al. [23] observed that BMD z-score serially increased across the calcium intake from 0.16 (calcium intake $400 \mathrm{mg} /$ day) to 0.18 (calcium intake $950 \mathrm{mg} /$ day) and 0.30 when calcium intake was $1400 \mathrm{mg} /$ day. Dietary calcium interacts with vitamin D metabolism [27]. Depending on the supply of vitamin $\mathrm{D}$ to the body, calcium absorption ranges from $10 \%$ to $80 \%$. Therefore, an unsatisfactory supply of vitamin D may result in calcium and phosphate imbalance and, as a consequence, the development of bone disturbances. About 50-60\% of our children from both groups had low dietary intake of vitamin D (below $5 \mu \mathrm{g} /$ day). Only $12 \%$ of CMA patients were supplemented with vitamin D. Our results are in accordance with other researchers, who observed deficiency in this vitamin in CMA patients $[25,26,28]$.

Similar to the study conducted by Hidvegi et al. [15], we did not observe any significant difference in the serum concentrations of calcium, phosphate and magnesium between patients and controls. Overall serum 25-hydroxyvitamin D status was normal in the majority of the studied children. However, about $25 \%$ of the children from both groups had an insufficient level of this vitamin (below $20 \mathrm{ng} / \mathrm{ml}$ ). Thirty-five percent of the children had appropriate levels of 25-hydroxyvitamin D (above $30 \mathrm{ng} / \mathrm{ml}$ ). Huang et al. [9] observed significantly lower levels of bone turnover markers at serum vitamin D values below $30 \mathrm{ng} / \mathrm{ml}$. The importance of calcium and vitamin $D$ for bone metabolism is confirmed by the finding of a correlation between these parameters and markers of bone turnover in our study.

Similar to our previous investigations [16], we observed no significant difference in total ALP, OC and CTX levels between patients and controls. However, activity of BALP was significantly higher in CMA children than in the healthy ones $(p<0.01)$. Our findings are partially consistent with those of a study conducted by Hidvegi et al. [15], who observed higher serum ALP levels, similar OC and lower CTX concentrations in children with CMA than in the controls. Elevated serum BALP activity in relation to osteocalcin concentration might cause inadequate bone mineralization. Therefore we assume that disturbances in bone formation markers may affect the skeletal condition of CMA children.

The coupling of bone formation and resorption is mediated through the RANK/RANKL/OPG path- way. Osteoprotegerin is considered an important marker of bone synthesis. Decreased serum OPG level may indicate higher risk of bone abnormalities. RANKL is related to mature osteoclast activation for bone resorption and is considered an important marker of bone resorption. Lower OPG/RANKL ratio demonstrates an increase in bone resorption. The data concerning relationships between OPG and RANKL concentrations, bone metabolism and BMD are scarce and fairly ambiguous $[29,30]$. In the study conducted by Xu et al. [31] patients with rheumatoid arthritis showed significantly higher serum levels of RANKL, lower serum levels of OPG and a lower OPG/RANKL ratio compared with the healthy controls. Similar findings demonstrating a reduced OPG/RANKL ratio were reported in girls with anorexia nervosa, which could partly explain the bone loss that occurs in these patients $[32,33]$. No research has been done regarding the levels of cytokines OPG and RANKL in patients with cow's milk allergy. In our study we observed similar levels of OPG and a significant trend towards higher levels of RANKL in children with CMA compared to the controls. Hence, the ratio of OPG/RANKL in this group of patients was lower than in healthy children. Increased levels of RANKL could contribute to the mature osteoclast differentiation, bone resorption activation and in consequence decrease in BMD observed in children with food allergy.

According to recent reports, fetuin-A is also involved in the regulation of calcium-phosphate balance. This highly pleomorphic protein is truly a systemic regulator of mineralization. Studies on fetuin-A deficient mice suggested that this protein mediates the transport of minerals from the extracellular space and regulates the process of matrix mineralization in osteoblastic cells [14, 34]. In the study of Rasul et al. [35] an association of fetuinA levels with markers of bone turnover in patients with type 2 diabetes was observed. There are no data on the role of fetuin-A in patients with cow's milk allergy. In our study, fetuin-A levels did not differ significantly between the two groups of children. This could be due to the fact that our patients were provided with medical and nutritional care regularly, had no signs of malnutrition, and anthropometric parameters were comparable with the controls.

It should be noted that this study has some limitations. Firstly, we did not perform densitometric measurements of BMD in the studied children, because they were treated with a dairy-free diet for about one year, which is a significantly shorter period of time compared to the observations of other authors [36]. Another limitation is related to the fact that some people have serum RANKL levels below the limit of detection. This limited patients with a calculated OPG/RANKL ratio. In our study 
about $20 \%$ of patients with cow's milk allergy and $10 \%$ of healthy children had undetectable levels of RANKL.

In conclusion, the results of this study suggest some changes in the profile of biochemical bone metabolism markers in children with cow's milk allergy. The lower OPG/RANKL ratio seems to indicate that some inadequacies exist regarding the balance between OPG and RANKL, which might contribute to an increase in bone resorption in these patients. A careful follow-up of patients with CMA should include the monitoring of calcium and vitamin $\mathrm{D}$ as well as bone metabolism markers during long-term elimination diets. The diets of children with CMA should be prescribed individually according to the foods to be eliminated, and the nutritional status and age of the child, with eventual supplementation.

\section{References}

1. Jarvinen KM, Chatchatee P. Mammalian milk allergy: clinical suspicion, cross-reactivities and diagnosis. Curr Opin Allergy Clin Immunol 2009; 9: 251-8.

2. Torkaman M, Amirsalari S, Saburi A, et al. Cow's milk protein allergy in infants and their response to avoidance. J Clin Diag Res 2012; 6: 615-8.

3. Kneepkens CMF, Meijer Y. Clinical practice. Diagnosis and treatment of cow's milk allergy. Eur J Pediatr 2009; 168: 891-6.

4. Vieira MC, Morais MB, Spolidoro JVN, et al. A survey on clinical presentation and nutritional status of infants with suspected cow's milk allergy. BMC Pediatr 2010; 10: 25.

5. Jurimae J. Interpretation and application of bone turnover markers in children and adolescents. Curr Opin Pediatr 2010; 22: 494-500.

6. Szulc P, Seeman E, Delmas PD. Biochemical measurements of bone turnover in children and adolescents. Osteoporosis 2000; 11: 281-94.

7. Ambroszkiewicz J, Gajewska J, Laskowska-Klita T. Serum osteocalcin and bone alkaline phosphatase in health children in relation to age and gender. Med Wieku Rozwoj 2002; 3: 267-72.

8. Rauchenzauner M, Schmid A, Heinz-Erian P, et al. Sexand age specific reference curves for serum markers of bone turnover in healthy children from 2 months to 18 years. J Clin Endocrinol Metab 2007; 92: 443-9.

9. Huang Y, Eapen E, Steele S, Grey V. Establishment of reference intervals for bone markers in children and adolescents. Clin Biochem 2011; 44: 771-8.

10. Kostenuik PJ, Shalbhoub V. Osteoprotegerin: a physiological and pharmacological inhibitor of bone resorption. Curr Pharm Des 2001; 7: 613-35.

11. Indridason OS, Franzson L, Sigurdsson G. Serum osteoprotegerin and its relationship with bone mineral density and markers of bone turnover. Osteoporos Int 2005; 16: 417-23.

12. Wagner D, Fahrleitner-Pammer A. Levels of osteoproteregin (OPG) and receptor activator for nuclear factor kappa B ligand (RANKL) in serum: are they of any help? Wien Med Wochenschr 2010; 160: 452-7.

13. Price PA, Toroian D, Lim JE. Mineralization by inhibitor exclusion: the calcification of collage with fetuin. J Biol Chem 2009; 284: 17092-101.
14. Jahnen-Dechent W, Heiss A, Schafer C, Ketteler M. FetuinA regulation of calcified matrix metabolism. Circ Res 2011; 108: 1494-509.

15. Hidvegi E, Arato A, Cserhati E, Horvath C, Szabo A, Szabo A. Slight decrease in bone mineralization in cow milksensitive children. JPGN 2003; 36: 44-9.

16. Rowicka G, Ambroszkiewicz J, Strucińska M, Dyląg H, Gołębiowska-Wawrzyniak M. The evaluation of selected parameters of calcium and phosphorus metabolizm in children with cow's milk allergy. Med Wieku Rozwoj 2012; 16: 109-16.

17. Palczewska I, Niedzwiecka Z. Somatic development indices in children and youth of Warsaw. Med Wieku Rozwoj 2001; 2 (Suppl. 1): 18-118.

18. Jarosz M, Bułhak-Jachymczyk B. Normy Żywienia Człowieka. Podstawy prewencji otyłości i chorób niezakaźnych. PZWL, Warszawa 2008.

19. Cashman KD, Hill TR, Lucey AJ, et al. Estimation of the dietary requirement for vitamin $D$ in healthy adults. Am J Clin Nutr 2008; 88: 1535-42.

20. Pearson D, Barreto-Chang O, Shepard WE, Greene A, Longhurst C. Vitamin D-deficient rickets in a child with cow`s milk allergy. Nutr Clin Pract 2010; 5: 394-8.

21. Morris HA, Turner AG, Anderson PH. Vitamin-D regulation of bone mineralization and remodeling during growth. Fron Biosci (Elite Ed) 2012; 4: 677-89.

22. Konstantynowicz J, Kaczmarski M, Piotrowska-Jastrzebska J, Sienkiewicz J. Densitometric evaluation of mineral deposits in children and young people with food sensitivity who were treated by diet therapy. Pol Merkur Lekarski 1998; 5: 203-7.

23. Henderson RC, Haves PR. Bone mineralization in children and adolescents with a milk allergy. Bone Miner 1994; 27: 1-12.

24. Infante D, Tormo R. Risk of inadequate bone mineralization in diseases involving long-term suppression of dairy products. J Pediatr Gastroenterol Nutr 2000; 30: 310-3.

25. Black RE, Williams SM, Jones IE, Goulding A. Children who avoid drinking cow milk have low dietary calcium intakes and poor bone health. Am J Clin Nutr 2002; 76: 675-80.

26. Jensen VB, Jorgensen IM, Rasmussen KB, Molgaard C, Prahl P. Bone mineral status in children with cow milk allergy. Pediatr Allergy Immunol 2004; 15: 562-5.

27. Turner AG, Anderson PH, Morris HA. Vitamin D and bone health. Scand J Clin Lab Invest Suppl 2012; 243: 65-72.

28. Paganus A, Juntunen-Backman K, Savilahti E. Follow-up of nutritional status and dietary survey in children with cow's milk allergy. Acta Paediatr 1992; 81: 518-21.

29. Piedra M, Garcia-Unzueta MT, Berja A, et al. Single nucleotide polymorphisms of the OPG/RANKL system genes in primary hyperparathyroidism and their relationship with bone mineral density. BMC Med Genet 2011; 12: 168.

30. Gurban CV, Mederle O. The OPG/RANKL system and zinc ions are promoters of bone remodeling by osteoblast proliferation in postmenopausal osteoporosis. Rom J Morphol Embryol 2011; 52 (3 Suppl): 1113-9.

31. Xu S, Wang Y, Lu J, Xu J. Osteoprotegerin and RANKL in the pathogenesis of rheumatoid arthritis-induced osteoporosis. Rheumatol Int 2012; 32: 3397-403.

32. Munoz-Calvo MT, Barrios V, Garcia de Alvaro MT, et al. Maintained malnutrition produces a progressive decrease in (OPG)/RANKL ratio and leptin levels in patients with anorexia nervosa. Scand J Clin Lab 2007; 67: 387-93.

33. Ostrowska Z, Ziora K, Oświęcimska J, et al. RANKL/ RANK/OPG system and bone status in females with anorexia nervosa. Bone 2012; 50: 156-60. 
34. Mori K, Emoto M, Inaba M. Fetuin-A: a multifunctional protein. Recent Pat Endocr Metab Immune Drug Discov 2011; 5: 124-46.

35. Rasul S, lihan A, Reiter MH, et al. Levels of fetuin-A relate to the levels of bone turnover biomarkers in male and female [patients with type 2 diabetes. Clin Endocrinol (Oxf) 2012; 76: 499-505.

36. Czaja-Bulsa G, Miazgowski T, Sych Z. Risk factors of osteopenia in children with milk allergy and coeliac disease. Gastroenter Pol 2000; 7: 83-90. 